\title{
Impact of radiofrequency ablation for patients with varicose veins on the budget of the German statutory health insurance system
}

\author{
Alexander Kuhlmann ${ }^{1 *}$, Anne Prenzler ${ }^{1}$, Jan Hacker ${ }^{2}$ and J-Matthias Graf von der Schulenburg ${ }^{1}$
}

\begin{abstract}
Objectives: In contrast to other countries, surgery still represents the common invasive treatment for varicose veins in Germany. However, radiofrequency ablation, e.g. ClosureFast, becomes more and more popular in other countries due to potential better results and reduced side effects. This treatment option may cause less follow-up costs and is a more convenient procedure for patients, which could justify an introduction in the statutory benefits catalogue. Therefore, we aim at calculating the budget impact of a general reimbursement of ClosureFast in Germany.

Methods: To assess the budget impact of including ClosureFast in the German statutory benefits catalogue, we developed a multi-cohort Markov model and compared the costs of a "World with ClosureFast" with a "World without ClosureFast" over a time horizon of five years. To address the uncertainty of input parameters, we conducted three different types of sensitivity analysis (one-way, scenario, probabilistic).
\end{abstract}

Results: In the Base Case scenario, the introduction of the ClosureFast system for the treatment of varicose veins saves costs of about 19.1 Mio. € over a time horizon of five years in Germany. However, the results scatter in the sensitivity analyses due to limited evidence of some key input parameters.

Conclusions: Results of the budget impact analysis indicate that a general reimbursement of ClosureFast has the potential to be cost-saving in the German Statutory Health Insurance.

Keywords: Varicose veins, Varices, Costs, Cost analysis, Budget impact, ClosureFast, Stripping, Radiofrequency ablation

\section{Background}

Primary varicose veins are a degenerative disease of the wall of the vein in the superficial vein system of the legs. Various factors (e.g. pregnancy, physical inactivity) affect the characteristics and severity of varices over a lifetime [1]. Primary varicose disease has to be differentiated from less common secondary varicose veins which occur in the deep vein systems to conditions such as deep vein thrombosis, pelvic tumors or arteriovenous fistulae [2]. Besides a variety of symptoms of discomfort in the legs (e.g. itching, heaviness, and aching) [3], varicose veins can cause more severe complications, for instance

\footnotetext{
* Correspondence: ak@ivbl.uni-hannover.de

${ }^{1}$ Leibniz Universität Hannover, Center for Health Economics, Hannover, Germany

Full list of author information is available at the end of the article
}

ulceration, deep main vein insufficiency, varicophlebitis [1,4-6].

The range of reported prevalence data for primary varices is very wide ( $2-56 \%$ in men and $1-60 \%$ in women) due to variations in the study population, selection criteria, methods of measurement and disease definition [7-13]. The majority of the literature quotes a study from Callam, which estimates that the prevalence of visible tortuous varicose veins in an unselected Western adult population over the age of 15 years is between 10 and $15 \%$ for men and between 20 and 25\% for women [7]. According to the "Bonner Venenstudie" [13] 12.4\% of men and 15.8\% of women had varices without symptoms of chronic vein insufficiency in Germany in 2003. However, the occurrence of varicose veins varies by age [14]. Studies which estimate the incidence of primary varices are rare. Nevertheless, 
there exists a publication by Mäkivaara et al., who report an incidence rate of 13.5 per 1,000 person years (8.5 for men and 19.2 for women) [15].

Due to the high prevalence the treatment of patients with varicose veins places a substantial financial burden on the health care system. For example, the German Federal Statistical Office estimated health care costs due to varicose veins (ICD-10: I83 Varicose veins of lower extremities) at 790 Mio $€$ in 2008 [16]. Hence, analyses which give a deep insight into costs and benefits of different treatment patterns are important for the German health care sector in order to identify cost effective treatment options.

Several interventional (e.g. surgery, endovenous thermal ablations, sclerotherapy) and non-interventional treatments (e.g. compression therapy) of varicose veins exist and are approved for treatment in Germany. Despite the growing popularity of new minimally invasive endovenous treatments for varicose veins in other countries in the past decade, surgery still represents the standard intervention in Germany [17], since endovenous thermal ablations aren't covered by the general benefits catalogue of the Statutory Health Insurance (SHI). In contrast to conventional surgery which is often conducted in hospitals with general or regional anaesthesia, the majority of the minimally invasive techniques are performed as office based procedures using tumescent local anaesthesia [18].

Recently, a new endovenous thermal ablation named ClosureFast, which uses radiofrequency techniques to treat varicose veins, was introduced in the USA. This improved version of the ClosurePlus device promises reduced pain, improved Quality of Life (QoL) and a faster recovery after treatment in comparison to surgery. Furthermore, comparable effectiveness parameters are reported [18]. In addition, since ClosureFast is mainly performed in an outpatient setting, treatment costs may be reduced by avoiding costly inpatient procedures. Hence, an inclusion of ClosureFast in the general benefits catalogue of the German SHI should be considered. To explore the potential financial consequences an economic evaluation is necessary.

Besides cost-effectiveness models, budget impact analyses (BIA) are very important in the German setting. The purpose of a BIA is to estimate the affordability of a new health care intervention for health care decision-makers. The results of these models present the impact of an innovation on a national annual health care budget [19]. Such an analysis can be helpful to determine if ClosureFast is an affordable option for the German setting.

Therefore, aim of this study is to examine the budget impact of a general reimbursement of ClosureFast by the SHI in Germany.

Before presenting the model structure, input parameters and analysis procedure in the methods section, we want to give a short overview of the several alternative treatment options.

\section{Treatment options for varicose veins}

Treatment options for varicose veins can be divided into interventional and non-interventional procedures. Conservative, non-interventional treatments such as compression therapies with medical stockings and pantyhose can be used in every stage of the disease. However, they neither remove the varice nor hinder its development. In contrast, non-interventional treatments aim at alleviating the symptoms [1].

The interventional treatments can be categorized in sclerotherapy, endovenious thermal therapy and surgery. Surgical treatment of varicose veins includes high ligation (crossectomy) and saphenous vein stripping, with or without phlebectomy [20] and has been performed since the early 20th century. Until recently, high ligation and stripping was the standard treatment for patients with varicose veins demonstrating improvements in quality of life as well as reductions in symptoms and reoperation rates compared with high ligation and phlebectomies only [21-23]. However, various complications can occur following varicose vein surgery. Even though serious complications such as deep vein thrombosis (1 in 200 patients) or pulmonary embolism (1 in 600 patients) are rare [24], minor complications occur frequently. For instance, reported rates of wound complications including infection, haematoma and abscess formations vary from $3-10 \%$ [24,25].

Sclerotherapy techniques aim at inducing endothelial and vein wall damage in a controlled fashion by injecting toxic liquids or foam in the varice. This results in the obliteration of the varicose vein. Sclerotherapy is considered as the gold standard treatment for leg telangiectasias, venulectasias, and reticular veins [26]. A disadvantage is that the treatment of saphenous veins with non-foam sclerosing agents is associated with high recurrent rates $[27,28]$. However, recently, treatment with ultra-sound guided foam sclerotherapy (UGFS) has shown better results [29-31].

Minimally invasive endovenous thermal treatments include endovenous laser ablation (EVLA) and radiofrequency ablations (RFA). The aim of endovenous thermal ablation is the irreversible obliteration of the varice. For the EVLA procedure, a thin laser fiber is inserted in the vein under duplex ultrasound control and heated by laser energy to cause thermal damage of the vein wall. The ultrasound guided RFA technique uses radiofrequency energy which is directed through a small cathether inserted through a tiny insertion in the vein to heat up the varice and damage its vein wall. In different randomized trials, the first-generation RFA device VNUS ClosurePlus and EVLA showed comparable effectiveness to surgery; 
however, RFA was associated with reduced pain and improved QoL as well as a faster recovery after treatment [32-42].

In the following section, we will describe the methods used to explore the potential financial consequences of an introduction of ClosureFast in the German SHI.

\section{Methods}

To assess the budget impact of a "World with ClosureFast" compared to a "World without ClosureFast", a multi-cohort Markov model was developed and programmed in Microsoft Excel 2007.

The evaluation was conducted from the perspective of the SHI in Germany. The publication of the ISPOR task force [43] as well as the manuscript of Nuijten et al. [19] served as guidelines for the preparation of the BIA. Input parameters were derived from a systematic literature research. In addition, two medical experts in the field of varicose veins were contacted to provide expert opinions on present and future market shares of initial and secondary interventional treatment of varicose veins as well as resource use.

\section{Model structure}

The basic structure of the model was adapted from a recently published cost-effectiveness model of the National Institute for Health and Clinical Excellence (NICE) $[44,45]$, illustrated in Figure 1. (For the following description of the model structure see NICE [44,45].)
The time horizon of the model was five years with a cycle length of one month. Patients enter the model receiving initial interventional treatment for varicose veins (state: "1st treatment episode"). Following the completion of the treatment episode, patients move to the state "1st varices free episode", in which they do not require further treatment. They remain in this state until a varicose vein recurs. Hence, they transit to the state "physical symptoms of recurrent varicose veins (1)". A defined proportion of patients receive a 2 nd interventional treatment while the others are treated with conservative care in form of a compression therapy until the end of the model's time horizon (or death). Patients who undergo a second interventional treatment move on to the state "2nd varices free episode", where they remain until they experience a 2 nd clinical recurrence. In case of a 2 nd recurrence, patients only receive conservative care until the end of the model's time horizon (or death). Transition to death is possible from all states of the model. The annual risk of dying is the same in every health state. The monthly all-cause death probability was calculated on the basis of official life tables [46] (Table 1).

To calculate the budget impact, every month, a defined cohort had to enter the model receiving initial interventional treatment according to given market shares. Considering the time horizon of five years (2013-2017), the model included 60 patient cohorts. However, since recurrence rates play an important role in the treatment of recurrent varicose veins (see segment

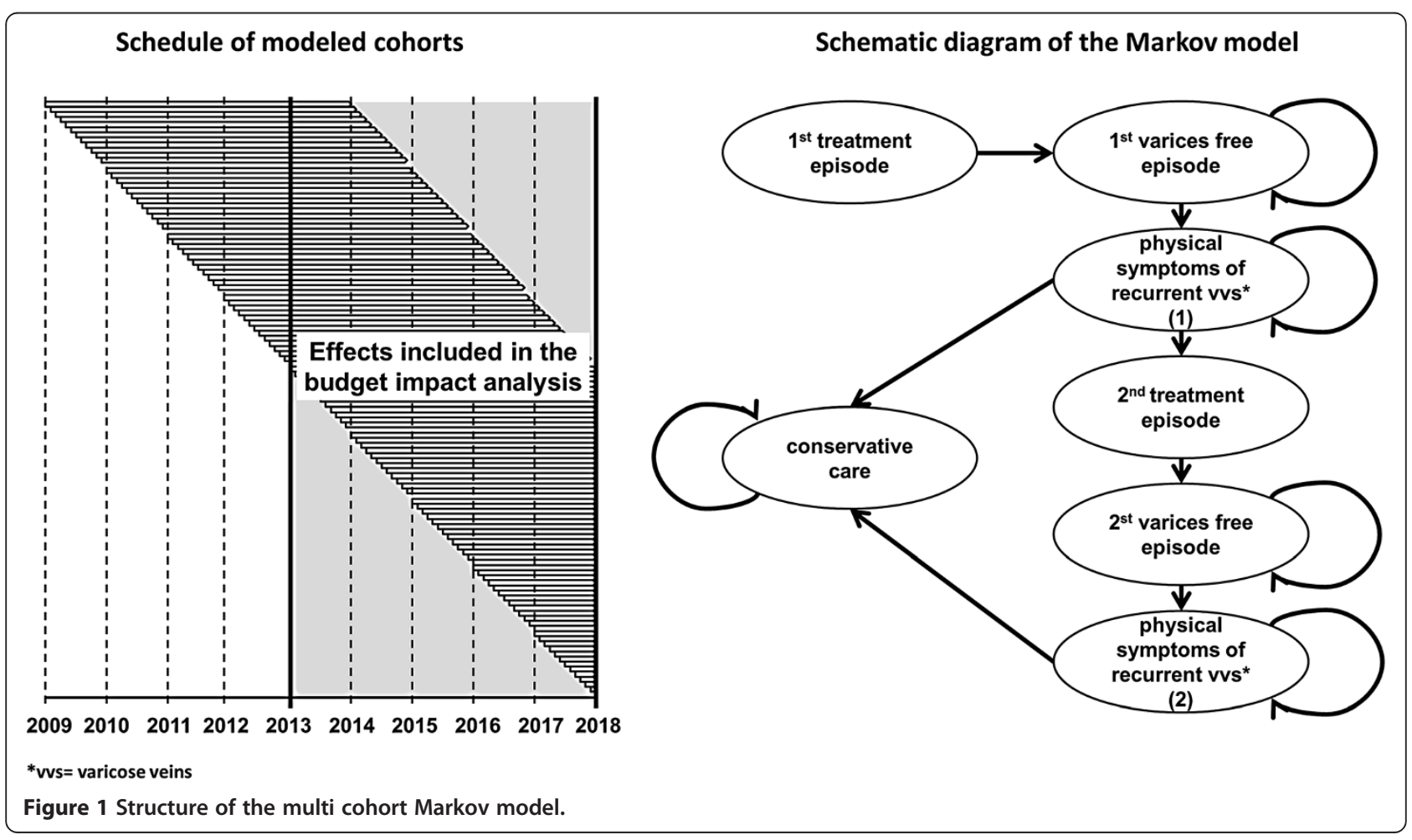




\section{Table 1 Key parameters of the model}

- treatment episode consists of interventional treatment for every patient and a top-up treatment (additional treatment in case of complications, i.e. vein has not been occluded or obliterated) for a defined proportion of patients (i.e. treated vein is not occluded or obliterated)

- maximum of two treatment episodes: initial interventional treatment for all patients and a second interventional treatment for a given proportion of patients with recurrent varicose veins

- no difference of effectiveness between initial and secondary interventional treatment for each procedure

- top-up treatment is always UGFS and has no influence on recurrence rates

- constant hazard of recurrence

- 6 month delay between onset of clinical recurrence and second treatment episode

- conservative care is given to patients with recurrent varicose veins who do not undergo a second treatment episode as clinical recurrence is not considered clinically meaningful and to all patients with a second recurrence

Source: NICE [44,45].

effectiveness) patients with an initial or 2nd interventional treatment of varices before 2013 should not be neglected. Hence, we added another 48 cohorts (four years) to the model and followed-up each of these cohorts for five years (see Figure 1).

\section{Patient cohorts and market shares of treatments for varicose veins}

German literature data exists only for the annual number of varicose vein surgeries performed in an inpatient setting. Göckeritz estimates that surgeries still account for about $90 \%$ of all interventional treatments for varicose veins in Germany [17]. Under the assumptions that the small number of patients treated with endovenous thermal ablations within the SHI can be neglected (expert opinion) and all top-up treatments are UGFS (see Table 1), about $95 \%$ of all interventional non-top-up treatments have to be surgical and 5\% sclerosing procedures. Furthermore, about $60 \%$ of varicose vein surgeries are undertaken in an outpatient setting according to experts' estimates.

If ClosureFast is introduced in the SHI benefit catalogue, the market shares will shift - in particular at the expense of surgery market shares. On the basis of expert opinion, we assume that ClosureFast accounts for $10 \%$ of all procedures in the year of its introduction and has an annual market growth of five percentage points each following year (Base Case assumption). The increase of the use of ClosureFast is assumed to reduce the market share of surgeries equally. The medical experts do not assume a reimbursement of EVLA by the SHI in the near future; therefore, EVLA treatment was not included in the budget impact analysis (Table 2).

In Germany, inpatient varicose vein surgeries are coded as OPS 5-385 within the G-DRG system. Based on the numbers of coded surgical procedures which were derived from the German Federal Statistical Office [47] as well as the above stated expert opinions on market shares, we calculated the size of the monthly patient cohorts. Table 3 shows the different steps of the calculation process in detail.

\section{Effectiveness and adverse events}

The effectiveness of the different treatment procedures was modeled via recurrence data. "Success" of interventional treatment was not considered in the model, as patients receive top-up treatments (additional treatment in case of complications, i.e. vein has not been occluded or obliterated) until the treatment episode is complete $[44,45]$ (NICE).

A recurrence describes varicose veins which occur in the same area of the treated varice, independently of the type of the initial treatment. Noppeney et al. distinguish between three causes of recurrent varices: technical failure of the initial treatment, neovascularisation and progression of the venous disease [55]. About 20\% of

Table 2 Assumed market shares of interventional treatments for varicose veins in Germany*

\begin{tabular}{lllll}
\hline Market shares & $\mathbf{2 0 1 3}$ & $\mathbf{2 0 1 4}$ & $\mathbf{2 0 1 5}$ & $\mathbf{2 0 1 6}$ \\
\hline World without ClosureFast (1st and 2nd treatment) & & & $\mathbf{2 0 1 7}$ \\
Surgery & 0.95 & 0.95 & 0.95 & 0.95 \\
UGFS & 0.05 & 0.05 & 0.05 & 0.05 \\
World with ClosureFast (1st and 2nd treatment) & & & 0.05 \\
Surgery & 0.85 & 0.80 & 0.75 & 0.70 \\
ClosureFast & 0.10 & 0.15 & 0.20 & 0.25 \\
UGFS & 0.05 & 0.05 & 0.05 & 0.05 \\
\hline
\end{tabular}

* Excluding top-up treatment. 
Table 3 Calculation of monthly patient cohorts

\begin{tabular}{|c|c|c|c|c|c|c|c|}
\hline & $\begin{array}{c}\text { Annual inpatient } \\
\text { surgeries OPS } \\
5-385^{*}\end{array}$ & $\begin{array}{l}\text { Annual inpatient } \\
\text { surgeries of } \\
\text { SHI patients }\end{array}$ & $\begin{array}{l}\text { Annual outpatient } \\
\text { surgeries of SHI } \\
\text { patients }\end{array}$ & $\begin{array}{l}\text { Annual total } \\
\text { surgeries of SHI } \\
\text { patients }\end{array}$ & $\begin{array}{l}\text { Annual total initial } \\
\text { surgeries of SHI } \\
\text { patients }\end{array}$ & $\begin{array}{l}\text { Annual total initial } \\
\text { surgeries + UGFS } \\
\text { of SHI patients }\end{array}$ & $\begin{array}{l}\text { Monthly total initial } \\
\text { surgeries + UGFS } \\
\text { of SHI patients }\end{array}$ \\
\hline 2009 & 147,445 & 125,328 & 187,992 & 313,321 & 250,657 & 263,849 & 21,987 \\
\hline 2010 & 146,279 & 124,337 & 186,506 & 310,843 & 248,674 & 261,762 & 21,814 \\
\hline 2011 & 146,351 & 124,398 & 186,598 & 310,996 & 248,797 & 261,891 & 21,824 \\
\hline $2012-2017$ & $146,000^{1}$ & 124,100 & 186,150 & 310,250 & 248,200 & 261,263 & 21,772 \\
\hline Calculation & I & $\begin{array}{c}\|=\mid \cdot 0.85(85 \% \text { of } \\
\text { patients in SHI) }{ }^{2}\end{array}$ & $\begin{array}{c}\mathrm{III}=\| \cdot 1.5 \text { (outpatient/ } \\
\quad \text { inpatient ratio) }\end{array}$ & $\begin{array}{l}\text { IV }=\|+\| I I \\
\text { (inpatient + } \\
\text { outpatient) }\end{array}$ & $\begin{array}{c}V=\mathrm{IV} \cdot 0.8 \text { (initial procedures } \\
\text { account for } 80 \% \text { of total } \\
\text { procedures) }\end{array}$ & $\begin{array}{c}\mathrm{VI}=\mathrm{V} \cdot 1 / 0.95 \text { (surgeries account for } \\
95 \% \text { of all non-top-up treatments) }\end{array}$ & $\mathrm{VII}=\mathrm{VI} \cdot 1 / 12$ \\
\hline
\end{tabular}

${ }^{1}$ Assumption.

German Federal Statistical Office [48]

${ }_{4}^{3}$ Expert opinion.

${ }_{5}^{4}$ [49-53].

on Göckeritz [17], NICE [44] and expert opinion.

* The annual inpatient surgeries do not reflect the number of treated patients per year but the number of inpatient reimbursed procedures. The annual number of patients treated in an inpatient setting is lower [54]. 
varicose surgeries are attributed to recurrences [49-53]. Differences in the initial treatment, the method of measuring recurrences and duration of follow-up make a comparison of recurrence rates difficult [56]. After surgical treatment of varicose veins and a follow-up period of three to eleven years, recurrence rates of $26-62 \%$ have been reported $[57,58]$. In addition, data indicates that the rate of recurrences increases over time [59].

To gather data on recurrence rates as well as adverse events of all relevant treatment options for varicose veins, we performed a structured literature search in 44 databases using the database search tool of the German Institute of Medical Documentation und Information (DIMDI). Additionally, we conducted a hand research. The search strategy targeted meta-analyses of RCTs for surgery and UGFS as well as RCTs for ClosureFast.

The systematic literature review identified five metaanalyses [32,44,60-62] which compared recurrence data as well as adverse events of RFA and surgery. Two of these studies [32,44] included a comparison between foam sclerotherapy and surgery. Only one RCT was found which reported recurrence rates as well as adverse events of ClosureFast in comparison with surgery and UGFS [18]. The study was also included in two of the identified meta-analyses [44,62]. In total, six RCTs [18,36,63-66] presenting relevant data on recurrence rates have been identified via the five meta-analyses. Table 7 of the Appendix presents an overview of the reported recurrence rates. Only Belcora et al. found a statistically significant difference in recurrences [63].

In the Base Case analysis, we used the effectiveness data reported by NICE. Using a network meta-analysis approach, the authors estimated a one-month recurrence probability of 0.008331 for surgery, 0.005833 for endovenous thermal ablations and 0.009141 for UGFS. However, only a combined probability for RFA and EVLA was calculated [44]. Since none of the other identified RCTs and meta-analyses found a statistically significant difference between RFA and surgery, we made the conservative assumption that ClosureFast had the same effectiveness as surgery.

Adverse events were not included in the analysis. The complications reported in different trials varied a lot and different measurement methods were used. According to a multidisciplinary Guideline Development Group, which currently develops the NICE guidelines for the diagnosis and management of varicose veins, adverse event profiles of the different interventions are similar to the extent that they can be neglected in health economic models $[44,45]$.

\section{Resource use and cost data}

Resource and cost data regarding the treatment of varicose veins as well as the resulting side effects are only available in the literature to a limited extent. Therefore, we have identified relevant treatment procedures and resource usage via expert opinion and official handbooks. Hence, we have evaluated the resource use from the perspective of the SHI in Germany, taking also into consideration patient copayments as well as discounts for medications given by the manufacturer and pharmacies as required by legal obligations in Germany. For this, the current German recommendations $[67,68]$ for the valuation of resource usage were applied to evaluate the costs from the perspective of the SHI. In the Base Case analysis, we assumed that costs of interventional treatments in 2012 and costs of compression therapy in 2011 (no newer data currently available) would stay stable over time. Considering the increasing costs of inpatient treatment of varicose veins in recent years, this is a conservative assumption, since rising prices of inpatient procedures would have a greater effect on overall surgery costs due to its higher inpatient ratio compared with ClosureFast. However, price assumptions were varied in sensitivity analyses, e.g. by using the mean annual price inflation rate of varice treatments between 2005 and 2012, in order to take the uncertainty regarding future price developments into account. The historic development of surgery and UGFS prices are shown in Table 8 of the Appendix.

In Germany, inpatient stays are reimbursed via lump sums (diagnosis related groups, DRG). In these payments, in general all expenses of the hospital, incl. medication costs, are included. Relevant DRG were identified via the German DRG-Catalogue [69] using the official German DRG Definition Handbook from 2012 [70] and evaluated from the perspective of the German SHI [67-70].

Regarding the outpatient setting, we applied the official German Uniform Valuation Scheme (EBM) [71] and identified relevant OPS-codes for outpatient operations for surgery as well as physician visits. Again, the above mentioned recommendations for the evaluation were used $[67,68]$. For general outpatient physician visits of SHI-insured persons, it is important to mention that the doctors are reimbursed via lump sum payments per quarter, independent from the number of visits of an individual patient per quarter.

The proportion of patients treated in an outpatient and inpatient setting, respectively, was identified via expert opinion, since no official figures or literature data was available. Due to the uncertainty of the proportions, extensive sensitivity analyses were performed.

Table 4 summarizes the costs and effectiveness as well as the setting of all interventional treatments for varicose veins which were included in the BIA. 
Table 4 Effectiveness, costs and setting of interventional treatments

\begin{tabular}{|c|c|c|}
\hline Parameter & Value & Source \\
\hline \multicolumn{3}{|l|}{ Interventional treatment effectiveness } \\
\hline \multicolumn{3}{|l|}{ Monthly probability of recurrence after 1 st and 2nd treatment } \\
\hline Surgery & 0.00833 & NICE [44] \\
\hline ClosureFast & 0.00833 & Assumption \\
\hline UGFS & 0.00914 & NICE [44] \\
\hline \multicolumn{3}{|l|}{ Probability of top-up treatment } \\
\hline Surgery & 0.05 & NICE [44] \\
\hline ClosureFast & 0.05 & NICE[44] \\
\hline UGFS & 0.20 & NICE [44] \\
\hline Probability of receiving 2 nd intervention after recurrence & 0.75 & NICE [44] \\
\hline \multicolumn{3}{|l|}{ Treatment setting and costs } \\
\hline \multicolumn{3}{|l|}{ Outpatient treatment proportion } \\
\hline Surgery & 0.60 & Assumption \\
\hline ClosureFast & 0.90 & Assumption \\
\hline UGFS & 1.00 & Assumption \\
\hline \multicolumn{3}{|l|}{ Inpatient treatment costs } \\
\hline Surgery & $2,218.02 €$ & DRG F39b \\
\hline ClosureFast & $2,218.02 €$ & DRG F39b \\
\hline \multicolumn{3}{|l|}{ Outpatient treatment costs } \\
\hline Surgery & $639.45 €$ & OPS-Code $5-385.70^{*}$ \\
\hline ClosureFast & $1,100.00 €$ & Assumption** \\
\hline UGFS & $47.23 €^{* * *}$ & EBM-Codes 03111, 30501, 30500 \\
\hline Monthly costs of conservative compression therapy & $11.45 €$ & Kemper et al. [72] \\
\hline
\end{tabular}

* incl. operation and post-operative treatment.

** Average reimbursement in sub contracts between manufacturer and statutory health insurance funds.

*** EBM-Code 03111: $30.84 €$, EBM-Code 30500: 16.30 €, EBM-Code 30501: $9.29 €$.

\section{Uncertainty}

Various key inputs of the model are based on expert opinions (e.g. outpatient ratio of treatments) or on limited evidence (e.g. recurrence rates of interventional treatments for varicose veins) which may result in high uncertainty of model outcomes. To test the robustness of the model, we conducted three types of sensitivity analyses. First, we performed one-way sensitivity analyses to assess the impact of variations in values of every input parameter on the results. In order to test how the results react to a simultaneous variation of several inputs, we assumed four reasonable alternative scenarios of which two scenarios (ClosureFast + and ClosureFast++) were based on input values more likely to favor a "World with ClosureFast" and two other scenarios based on input values more likely to favor a "World without ClosureFast" (ClosureFast- and ClosureFast--). The alternative scenarios are summarized and described in Table 9 of the Appendix. Furthermore, we calculated the budget impact of the Base Case and the 4 alternative scenarios for three different market uptakes of ClosureFast:

- Base Case market uptake (10 percent points in the year of introduction and 5 percent points in the following years)

- Fast market uptake (15 percent points in the year of introduction and 7,5 percent points in the following years)

- Slow market uptake (5 percent points in the year of introduction and 2,5 percent points in the following years)

Finally, uncertainty was assessed using a probabilistic sensitivity analysis (PSA). The PSA was carried out as a Monte Carlo simulation with 10,000 iterations, simultaneously drawing random numbers for most model inputs from the distributions listed in Table 10 of the Appendix.

The discount rate was set to $0 \%$ in all investigated scenarios (Base Case as well as sensitivity analyses), since 
discounting is - in contrast to cost-effectiveness models no typical procedure in BIA [73].

\section{Results}

\section{Base case}

According to the results of the Base Case, the introduction of ClosureFast for the treatment of varicose veins saves costs of about 19.1 Mio. $€$ over a time period of five years in Germany. Detailed results are shown in Table 5. Since we assumed equal effectiveness between ClosureFast and surgery, the inpatient and outpatient treatment costs as well as the proportion of inpatient procedures of ClosureFast and surgery, respectively, are the factors which affected the results the most. While the higher outpatient treatment costs of ClosureFast" increases total costs on the one hand, the smaller proportion of inpatient procedures reduces overall costs on the other hand. All in all, the substitution of outpatient for inpatient treatments overcompensate the higher costs of ClosureFast in the outpatient setting. Over a time horizon of five years, a total of 1,623,749 interventional treatments for varicose veins are performed in a "World without ClosureFast". Of these, about 38\% are inpatient procedures causing about $70 \%$ of total interventional treatment costs. In a "World with ClosureFast", according to the results, about $32 \%$ of interventional treatments for varicose veins are performed in an inpatient setting causing about $60 \%$ of the total interventional treatment costs.

\section{One-way sensitivity analysis}

Results of the one-way sensitivity analyses show that the model outcome is highly sensitive to variations in interventional treatment prices (inpatient as well as outpatient) and the proportion of outpatient treatments. For instance, a $10 \%$ increase in the ClosureFast outpatient price leads to additional costs of about 32 Mio $€$ in a "World with ClosureFast". On the other hand, a

\section{Table 5 Results of the base case analysis}

\begin{tabular}{|c|c|c|c|c|c|}
\hline & 2013 & 2014 & 2015 & 2016 & 2017 \\
\hline \multicolumn{6}{|l|}{ Total costs (cumulated)* } \\
\hline \multirow{2}{*}{ World without ClosureFast } & $402,442,098 €$ & $402,227,395 €$ & $402,175,107 €$ & $402,118,493 €$ & $402,118,493 €$ \\
\hline & $(402,442,098 €)$ & $(804,669,493 €)$ & $(1,206,844,600 €)$ & $(1,608,963,093 €)$ & $(2,011,081,587 €)$ \\
\hline \multirow{2}{*}{ World with ClosureFast } & $400,534,663 €$ & $399,367,497 €$ & $398,362,261 €$ & $397,352,918 €$ & $396,399,803 €$ \\
\hline & $(400,534,663 €)$ & $(799,902,160 €)$ & $(1,198,264,421 €)$ & $(1,595,617,339 €)$ & $(1,992,017,142 €)$ \\
\hline \multirow{2}{*}{ Difference } & $-1,907,435 €$ & $-2,859,898 €$ & $-3,812,846 €$ & $-4,765,575 €$ & $-5,718,690 €$ \\
\hline & $(-1,907,435 €)$ & $(-4,767,333 €)$ & $(-8,580,179 €)$ & $(-13,345,754 €)$ & $(-19,064,445 €)$ \\
\hline \multicolumn{6}{|l|}{ Inpatient costs (cumulated) } \\
\hline \multirow{2}{*}{ World without ClosureFast } & $274,282,077 €$ & $274,162,435 €$ & $274,137,354 €$ & $274,109,746 €$ & $274,109,746 €$ \\
\hline & $(274,282,077 €)$ & $(548,444,512 €)$ & $(822,581,865 €)$ & $(1,096,691,611 €)$ & $(1,370,801,358 €)$ \\
\hline \multirow{2}{*}{ World with ClosureFast } & $252,637,930 €$ & $241,709,792 €$ & $230,870,333 €$ & $220,030,426 €$ & $209,213,366 €$ \\
\hline & $(252,637,930 €)$ & $(494,347,722 €)$ & $(725,218,054 €)$ & $(945,248,480 €)$ & $(1,154,461,846 €)$ \\
\hline \multirow{2}{*}{ Difference } & $-21,644,147 €$ & $-32,452,643 €$ & $-43,267,021 €$ & $-54,079,320 €$ & $-64,896,380 €$ \\
\hline & $(-21,644,147 €)$ & $(-54,096,790 €)$ & $(-97,363,811 €)$ & $(-151,443,131 €)$ & $(-216,339,512 €)$ \\
\hline \multicolumn{6}{|c|}{ Outpatient costs (cumulated)** } \\
\hline \multirow{2}{*}{ World without ClosureFast } & $119,530,604 €$ & $119,478,465 €$ & $119,467,534 €$ & $119,455,503 €$ & $119,455,503 €$ \\
\hline & $(119,530,604 €)$ & $(239,009,068 €)$ & $(358,476,603 €)$ & $(477,932,106 €)$ & $(597,387,609 €)$ \\
\hline \multirow{2}{*}{ World with ClosureFast } & $139,267,316 €$ & $149,071,210 €$ & $158,921,709 €$ & $168,769,248 €$ & $178,633,193 €$ \\
\hline & $(139,267,316 €)$ & $(288,338,526 €)$ & $(447,260,235 €)$ & $(616,029,483 €)$ & $(794,662,676 €)$ \\
\hline \multirow{2}{*}{ Difference } & $19,736,712 €$ & $29,592,745 €$ & $39,454,175 €$ & $49,313,744.85 €$ & $59,177,690 €$ \\
\hline & $(19,736,712 €)$ & $(49,329,458 €)$ & $(88,783,632 €)$ & $(138,097,377 €)$ & $(197,275,067 €)$ \\
\hline \multicolumn{6}{|c|}{ Inpatient costs/outpatient costs ratio (of cumulated costs) } \\
\hline \multirow{2}{*}{ World without ClosureFast } & 2.29 & 2.29 & 2.29 & 2.29 & 2.29 \\
\hline & (2.29) & (2.29) & $(2.29)$ & $(2.29)$ & $(2.29)$ \\
\hline \multirow{2}{*}{ World with ClosureFast } & 1.81 & 1.62 & 1.45 & 1.30 & 1.17 \\
\hline & $(1.81)$ & $(1.71)$ & $(1.62)$ & $(1.53)$ & $(1.45)$ \\
\hline
\end{tabular}

* Including costs of conservative treatment.

** Excluding costs of conservative treatment. 
$10 \%$ price reduction of the ClosureFast outpatient treatment results in additional savings of the same amount. Variations in the values of other input parameters (monthly probability of recurrence, probability of requiring top-up treatment and probability of receiving a 2nd interventional treatment) only had minor effects on the model outcome. Results of all performed one-way sensitivity analyses are shown in Table 11 of the Appendix.

\section{Scenario analyses}

The results of the scenario analyses are presented in Table 6 . As one might expect, the introduction of ClosureFast saves more costs in the scenarios with input values favoring a "World with ClosureFast" compared with the Base Case. However, in the two other scenarios (ClosureFast-, ClosureFast-), the introduction of ClosureFast is not cost saving anymore and causes up to 300 Mio $€$ of additional costs for the SHI in five years. A variation of the market uptake does not change the results qualitatively; solely the total costs as well as the cost difference vary between a "World with ClosureFast" and a "World without ClosureFast".

\section{Probabilistic sensitivity analysis (PSA)}

According to the results of the PSA, illustrated in Figure 2, a "World with ClosureFast" saves costs with a probability of about $59 \%$ over a time horizon of five years. With a probability of $25 \%$ cost savings of over 75 Mio $€$ can be realized in a "World with ClosureFast". However, with the same probability (25\%) the introduction of ClosureFast is likely to cause additional costs of at least 37 Mio $€$ in the SHI. All in all, it has to be noted that there is high uncertainty regarding the results, which reflects the limited evidence of several key input parameters.

\section{Discussion}

This study is the first to analyze the budget impact of different treatment scenarios for patients with varicose veins in the German setting. According to the results, ClosureFast has the potential to be cost saving for the German SHI.

Our model calculated about 308,000 surgeries of varicose veins in the SHI per year. These figures are based on a combination of the annual number of varicose vein surgeries performed in an inpatient setting and expert opinion. Nüllen et al. estimated that over 350,000 surgery treatments for varices are performed every year in Germany, including private insured patients [74]. Since about $85 \%$ of the German population is covered by the SHI [48], the model calculation is in line with the estimation of Nüllen et al. Furthermore, based on the recurrence rates used in the Base Case, our model calculated 248,200 initial surgery procedures which accounts for a proportion of 80.5 percent of all surgery procedures. These results agree with findings in the literature that recurrence treatments account for about 20\% [49-53] of all surgery treatments for varicose veins.

In the Base Case scenario, ClosureFast is dominant compared to surgery, since it is cost-saving while being equally effective. This is a conservative estimation, since other studies report a higher effectiveness of ClosureFast [33]. Our findings are supported by the results of the NICE model which also reported dominance of ClosureFast [44]. To our knowledge, there is only one other BIA [75] (for the Ontario setting) which analyses the budget impact of radiofrequency ablation. In contrast to our Base Case analysis, the authors conclude that the introduction of radiofrequency ablation leads to additional costs [75]. A cost-effectiveness study, conducted by Gohel et al., estimated less costs for RFA compared to stripping but also inferior outcomes [76]. In contrast to our analysis, Gohel

Table 6 Results of the scenario analyses after 5 years

\begin{tabular}{|c|c|c|c|c|c|}
\hline & Base case & ClosureFast+ & ClosureFast++ & ClosureFast- & ClosureFast- \\
\hline \multicolumn{6}{|c|}{ Base Case market uptake of ClosureFast (10 percent points in the year of introduction and 5 percent points in the following years) } \\
\hline World without ClosureFast & $2,011,081,587 €$ & $2,116,615,576 €$ & $2,431,191,408 €$ & $1,938,122,196 €$ & $1,588,229,622 €$ \\
\hline World with ClosureFast & $1,992,017,142 €$ & $2,039,393,961 €$ & $2,244,025,455 €$ & $1,996,246,708 €$ & $1,829,572,902 €$ \\
\hline Difference & $-19,064,445 €$ & $-77,221,615 €$ & $-187,165,953 €$ & $58,124,512 €$ & $241,343,280 €$ \\
\hline \multicolumn{6}{|c|}{ Fast market uptake of ClosureFast ( 15 percent points in the year of introduction and 7.5 percent points in the following years) } \\
\hline World without ClosureFast & $2,011,081,587 €$ & $2,116,615,576 €$ & $2,431,191,408 €$ & $1,938,122,196 €$ & $1,588,229,622 €$ \\
\hline World with ClosureFast & $1,982,484,920 €$ & $2,001,065,612 €$ & $2,152,055,284 €$ & $2,025,308,963 €$ & $1,913,810,466 €$ \\
\hline Difference & $-28,596,667 €$ & $-115,549,964 €$ & $-279,136,124 €$ & $87,186,767 €$ & $325,580,844 €$ \\
\hline \multicolumn{6}{|c|}{ Slow market uptake of ClosureFast ( 5 percent points in the year of introduction and 2.5 percent points in the following years) } \\
\hline World without ClosureFast & $2,011,081,587 €$ & $2,116,615,576 €$ & $2,431,191,408 €$ & $1,938,122,196 €$ & $1,588,229,622 €$ \\
\hline World with ClosureFast & $2,001,549,364 €$ & $2,077,910,616 €$ & $2,337,070,830 €$ & $1,967,184,452 €$ & $1,743,326,614 €$ \\
\hline Difference & $-9,532,223 €$ & $-38,704,960 €$ & $-94,120,578 €$ & $29,062,256 €$ & $155,096,992 €$ \\
\hline
\end{tabular}




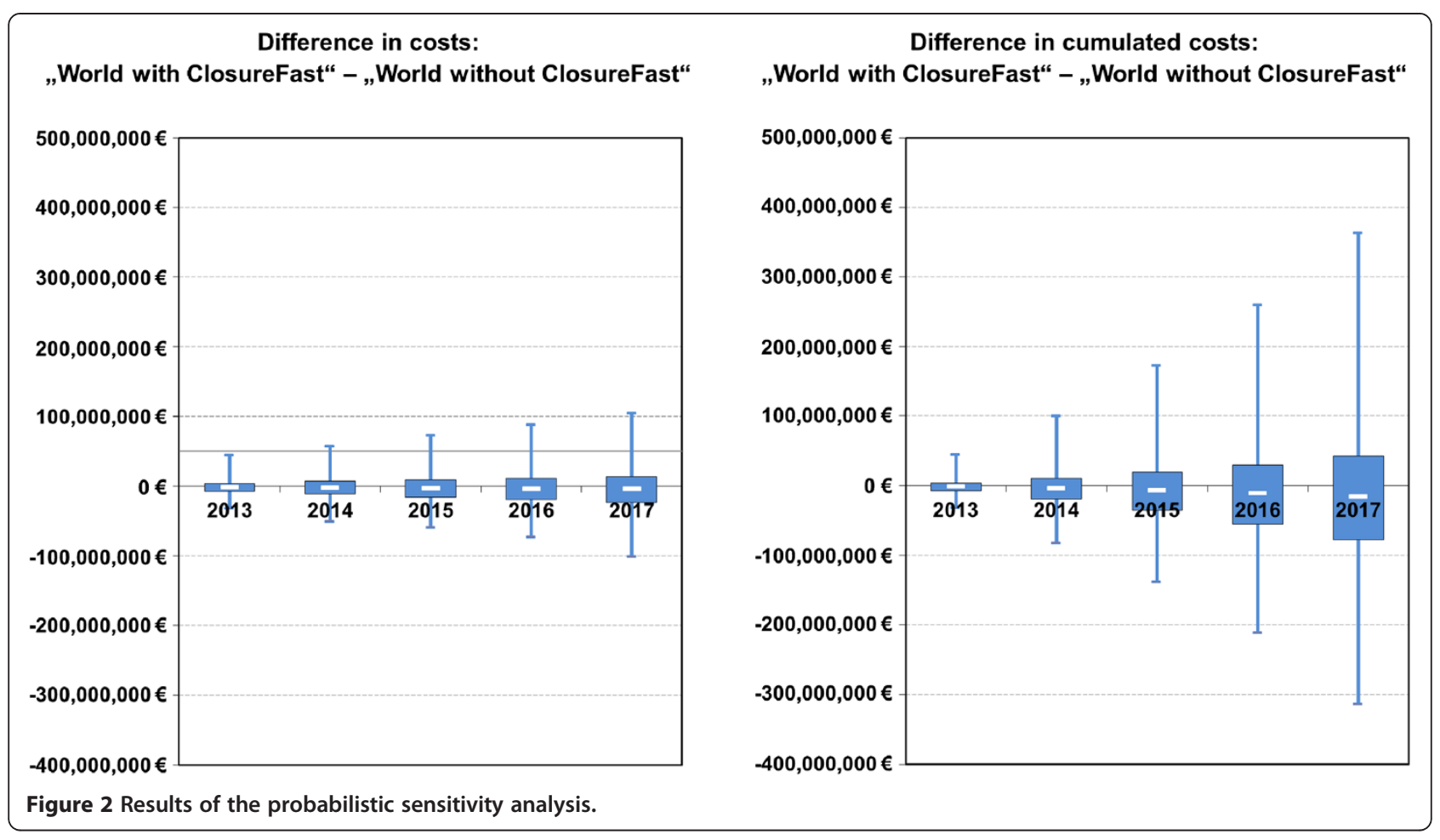

et al. used effectiveness data of ClosurePlus for their model and only took recurrences over a time horizon of three month into account [76].

The evaluation was conducted from the perspective of the SHI in Germany. Hence, indirect costs of work loss were not included in the analysis. Considering the shorter time to resume work after RFA treatment compared with surgery $[18,32,62]$, cost savings of introducing ClosureFast into the general benefit catalogue of the SHI should be even higher from a social perspective.

This study has some limitations, especially due to a lack of solid data in the literature. The lack of evidence of several key input parameters (in particular expert opinion for the treatment setting) resulted in high uncertainty regarding the outcomes of the model. In addition, there is only limited evidence regarding the effectiveness of treatments for varicose veins in preventing recurrences in the short term and particularly in the long term. Randomized RCTs with high number of patients are missing. Due to the insufficient power, the RCTs $[18,36,64,65]$, which were conducted in this indication could not show any statistical differences in recurrence rates between different RFA and surgery. Therefore, there is urgent need of high quality RCTs.

In general, due to the specialty of the reimbursement system in Germany, the results of this model are not directly transferable to foreign settings. Furthermore, as described earlier, the treatment strategies differ from foreign settings. For instance, surgery is still the dominant treatment strategy in Germany and EVLA plays no role. However, the model structure allows for incorporating EVLA into the analysis and can be adapted to other settings.

\section{Conclusions}

The analysis suggests that the introduction of ClosureFast for patients with varicose veins is cost-saving compared to the status quo in the German SHI setting. Even though the procedure ClosureFast is more expensive in an outpatient setting, cost savings occur due to a substitution of outpatient for inpatient treatments. However, the results scatter in the sensitivity analyses due to limited evidence of some key input parameters.

\section{Ethical approval for research}

Ethical approval is not needed for budget impact analyses.

\section{Appendix}

The files in the appendix provide additional information on reported recurrence rates of varicose veins after interventional treatment (Table 7), the development of SHI prices of interventional treatments for varicose veins (Table 8), a detailed summary and description of all relevant input parameters for the scenario (Table 9) and the probabilistic sensitivity analysis (Table 10) as well as the results of the one-way sensitivity analyses (Table 11). 
Table 7 Recurrence rates of relevant treatment options reported in RCTs

\begin{tabular}{|c|c|c|c|}
\hline Author & Year & Length of follow-up in months (number of patients at last follow up) & Number of patients (limbs) \\
\hline
\end{tabular}

\section{ClosureFast vs. Surgery vs. UGFS}

\section{ClosureFast: 125 (148) \\ Surgery: 125 (143) \\ UGFS: 125 (145)}

\section{ClosurePlus vs. Surgery}

Perälä [36]

2005

Lurie [64]

Helmy Elkaffes [65]

24 (ClosurePlus: 81 Surgery: 81)

\section{UGFS vs. Surgery}

Shadid [66]

24 (UGFS: 213 Surgery: 177)
ClosurePlus: 15 (15)

Surgery: 13 (13)

ClosurePlus: 43 (44)

Surgery: 36 (36)

ClosurePlus: 90 (90)

Surgery: 90 (90)

UGFS: 230 (230)

Surgery: 200 (200)

Recurrence rate

ClosureFast: $9 / 124=7.26 \%$

Surgery: $16 / 108=14.81 \%$

UGFS: $17 / 123=13.82 \%$

Odds ratio (ClosureFastvs Surgery): 0.45

Odds ratio (ClosureFastvs UGFS): 0.49

Odds ratio (UGFS vs Surgery): 0.92

ClosurePlus: 5/15 = 33.33\%

Surgery: $3 / 13=23.1 \%$

Odds ratio: 1.67

ClosurePlus: 5/36 = 13.89\%

Surgery: $6 / 29=20.69 \%$

Odds ratio: 0.62

ClosurePlus: $12 / 81=14.81 \%$

Surgery: $9 / 81=11.11 \%$

Odds ratio: 1.39

UGFS: $24 / 213=11.27 \%$

Surgery: $16 / 177=9.04 \%$

Odds ratio: 1.28

\section{Foam Sclerotherapy vs Surgery}

Belcaro [63]

2000

120

Foam Sclerotherapy: 148

Foam Sclerotherapy: 56/148 $=37.84 \%$

Surgery: 155

Surgery: $38 / 155=24,52 \%$

Odds Ratio: 1.87 
Table 8 Development of SHI prices of interventional treatments for varicose veins

\begin{tabular}{|c|c|c|c|}
\hline & & & \\
\hline & Inpatient* & Outpatient ${ }^{* *}$ & only) ${ }^{* *}$ \\
\hline 2004 & $1,811.71 €$ & $n / s$ & $n / s$ \\
\hline 2005 & $1,726.92 €$ & $n / s$ & $n / s$ \\
\hline 2006 & $1,745.41 €$ & $n / s$ & $n / s$ \\
\hline 2007 & $1,821.26 €$ & $\mathrm{n} / \mathrm{s}$ & $\mathrm{n} / \mathrm{s}$ \\
\hline 2008 & $1,861.95 €$ & $n / s$ & $\mathrm{n} / \mathrm{s}$ \\
\hline 2009 & $2,039.82 €$ & $638.59 €$ & $56.35 €$ \\
\hline 2010 & $2,066.19 €$ & $639.45 €$ & $56.43 €$ \\
\hline 2011 & $2,074.22 €$ & $639.45 €$ & $56.43 €$ \\
\hline 2012 & $2,218.02 €$ & $639.45 €$ & $56.43 €$ \\
\hline 2013 & $n / s$ & $645.20 €$ & $56.93 €$ \\
\hline
\end{tabular}

* InEK GmbH - Institute for the Hospital Remuneration System: Diagnosis Related Group-Catalogue 204-2012. Düsseldorf: Dt. Krankenhaus-Verl.-Ges.; 2003-2011.

** National Association of Statutory Health Insurance Physicians: Uniform Value Scale 2009-2012. http://www.kbv.de.

Table 9 Input parameters modified in the scenario analyses ${ }^{\#}$

\begin{tabular}{|c|c|c|c|c|c|}
\hline Parameter & Base case & ClosureFast+ & ClosureFast++ & ClosureFast- & ClosureFast- \\
\hline \multicolumn{6}{|c|}{ Monthly probability of recurrence after $1 \mathrm{st}$ and $2 \mathrm{nd}$ treatment } \\
\hline Surgery & 0.00833 & 0.00833 & $0.01326^{* *}$ & 0.00833 & $0.00490^{* * *}$ \\
\hline ClosureFast & 0.00833 & $0.00583^{*}$ & $0.00630^{* *}$ & 0.00833 & $0.00666^{* * *}$ \\
\hline UGFS & 0.00914 & 0.00914 & 0.00914 & 0.00914 & 0.00914 \\
\hline
\end{tabular}

* Monthly recurrence rate of endovenous thermal ablation reported by NICE [45]; ** monthly recurrence rate based on Rasmussen et al. [18]; *** monthly recurrence rates based on Helmy Elkaffas et al. [65]

\section{Surgery outpatient treatment ratio}

$\begin{array}{lllllr}2013 & 0.600 & 0.600 & 0.600 & 0.600 & 0.660^{* *} \\ 2014 & 0.600 & 0.600 & 0.600 & 0.615^{*} & 0.690^{* *} \\ 2015 & 0.600 & 0.600 & 0.600 & 0.630^{*} & 0.720^{* *} \\ 2016 & 0.600 & 0.600 & 0.600 & 0.645^{*} & 0.750^{* *} \\ 2017 & 0.600 & 0.600 & 0.600 & 0.660^{*} & 0.780^{* *}\end{array}$

* outpatient treatment ratio increases by 1.5 percent points per year; ** outpatient treatment ratio 6 percent points higher in 2013 and increases by 3 percent points per year

Surgery inpatient costs

\begin{tabular}{|c|c|c|c|c|c|}
\hline 2013 & $2,218.02 €$ & $2,270.54 €^{*}$ & $2.323,06 €^{* *}$ & $2,218.02 €$ & $2,218.02 €$ \\
\hline 2014 & $2,218.02 €$ & $2,324.30 €^{*}$ & $2.433,07 €^{* *}$ & $2,218.02 €$ & $2,218.02 €$ \\
\hline 2015 & $2,218.02 €$ & $2,379.34 €^{*}$ & $2.548,30 €^{* *}$ & $2,218.02 €$ & $2,218.02 €$ \\
\hline 2016 & $2,218.02 €$ & $2,435.68 €^{*}$ & $2.668,98 €^{* *}$ & $2,218.02 €$ & $2,218.02 €$ \\
\hline 2017 & $2,218.02 €$ & $2,439.35 €^{*}$ & $2.795,37 €^{* *}$ & $2,218.02 €$ & $2,218.0$ \\
\hline
\end{tabular}

* mean annual price inflation rate 2004-2012 (2.37\%); ** mean annual price inflation rate 2004-2012 times two

\section{Surgery inpatient treatment costs}

\begin{tabular}{|c|c|c|c|c|c|}
\hline 2013 & $639.45 €$ & $645.20 €^{*}$ & $645.20^{*} €$ & $639.45 €$ & $639.45 €$ \\
\hline 2014 & $639.45 €$ & $645.20 €^{*}$ & $645.20^{*} €$ & $639.45 €$ & $639.45 €$ \\
\hline 2015 & $639.45 €$ & $645.20 €^{*}$ & $645.20^{*} €$ & $639.45 €$ & $639.45 €$ \\
\hline 2016 & $639.45 €$ & $645.20 €^{*}$ & $645.20^{*} €$ & $639.45 €$ & $639.45 €$ \\
\hline 2017 & $639.45 €$ & $645.20 €^{*}$ & $645.20^{*} €$ & $639.45 €$ & 9.45 \\
\hline
\end{tabular}

* price based on new EBM point value $(0.035363 €$ per point) 
Table 9 Input parameters modified in the scenario analyses" (Continued)

\section{ClosureFast outpatient treatment ratio}

2013

2014

2015

2016

2017

* outpatient treatment ration 5 percent points lower than estimated by experts

$\begin{array}{lllll}0.90 & 0.90 & 0.95 & 0.90 & 0.85^{*} \\ 0.90 & 0.90 & 0.95 & 0.90 & 0.85^{*} \\ 0.90 & 0.90 & 0.95 & 0.90 & 0.85^{*} \\ 0.90 & 0.90 & 0.95 & 0.90 & 0.85 * \\ 0.90 & 0.90 & 0.95 & 0.90 & 0.85 *\end{array}$

\section{ClosureFastinpatient costs}

\begin{tabular}{|c|c|c|c|c|c|}
\hline 2013 & $2,218.02 €$ & $2,270.54 €^{*}$ & $2,023.06 €^{* *}$ & $2,218.02 €$ & $2,218.02 €$ \\
\hline 2014 & $2,218.02 €$ & $2,324.30 €^{*}$ & $2,118.87 €^{* *}$ & $2,218.02 €$ & $2,218.02 €$ \\
\hline 2015 & $2,218.02 €$ & $2,379.34 €^{*}$ & $2,219.21 €^{* *}$ & $2,218.02 €$ & $2,218.02 €$ \\
\hline 2016 & $2,218.02 €$ & $2,435.68 €^{*}$ & $2,324.31 €^{* *}$ & $2,218.02 €$ & $2,218.02 €$ \\
\hline 2017 & $2,218.02 €$ & $2,493.35 €^{*}$ & $2,434.38 €^{* *}$ & $2,218.02 €$ & $2,218.02 €$ \\
\hline
\end{tabular}

* mean annual price inflation rate 2004-2012 (2,37\%); ** mean annual price inflation rate 2004-2012 times two + inpatient costs of ClosureFast $300 €$ lower than surgery inpatient costs in 2013

\section{ClosureFast inpatient costs}

\begin{tabular}{|c|c|c|c|c|c|}
\hline 2013 & $1,100.00 €$ & $1,000.00 €$ & $900.00 €$ & $1,300.00 €$ & $1,500.00 €$ \\
\hline 2014 & $1,100.00 €$ & $1,000.00 €$ & $900.00 €$ & $1,300.00 €$ & $1,500.00 €$ \\
\hline 2015 & $1,100.00 €$ & $1,000.00 €$ & $900.00 €$ & $1,300.00 €$ & $1,500.00 €$ \\
\hline 2016 & $1,100.00 €$ & $1,000.00 €$ & $900.00 €$ & $1,300.00 €$ & $1,500.00 €$ \\
\hline 2017 & $1,100.00 €$ & $1,000.00 €$ & $900.00 €$ & $1,300.00 €$ & $1,500.00 €$ \\
\hline \multicolumn{6}{|c|}{ Market shares } \\
\hline 2013-2017 & Base Case & Base Case & Base Case & Base Case & * \\
\hline \multicolumn{6}{|c|}{ Volume increase of the market } \\
\hline 2013-2017 & Base Case & Base Case & Base Case & Base Case & $* *$ \\
\hline
\end{tabular}

\# BaseCase values were maintained for all other input parameters.

* Base Case; but ClosureFast takes 2.5 percent points of UGFS market shares in the first year.

** Due to the introduction of ClosureFast the volume of the market increases by 0.5 percent points every year. 
Table 10 Means, standard errors and distributions of input parameters varied in the probabilistic sensitivity analysis

\begin{tabular}{|c|c|c|c|}
\hline & Mean & Standard error & Distributi \\
\hline \multicolumn{4}{|c|}{ Initial intervention population } \\
\hline 2013-2017 & 261,263 & 2,500 & normal \\
\hline \multicolumn{4}{|c|}{ Monthly survival probability } \\
\hline & 0.99944 & 0.0001 & normal \\
\hline \multicolumn{4}{|c|}{ Monthly probability of recurrence after initial and 2 nd interventional treatment } \\
\hline Surgery & 0.008331 & 0.00164 & beta \\
\hline ClosureFast & 0.008331 & 0.00176 & beta \\
\hline UGFS & 0.009141 & 0.00105 & beta \\
\hline
\end{tabular}

Probability of requiring top-up treatment after initial and 2nd interventional treatment

$\begin{array}{llll}\text { Surgery } & 0.05000 & 0.00021 & \text { uniform } \\ \text { ClosureFast } & 0.05000 & 0.00021 & \text { uniform } \\ \text { UGFS } & 0.20000 & 0.00333 & \text { uniform }\end{array}$

Probability of receiving 2 nd interventional treatment
0.75000
0.02083
uniform

Weighted mean of in- and outpatient interventional treatment costs (per procedure)

$\begin{array}{lccc}\text { Surgery } & 1,270.88 € & 190.63 € & \text { gamma } \\ \text { ClosureFast } & 1,211.80 € & 181.77 € & \text { gamma } \\ \text { UGFS } & 56.43 € & 8.46 € & \text { gamma }\end{array}$

Monthly costs of compression therapy
$11.45 €$
$1.14 €$
gamma

ClosureFast market uptake (in percent points)

\begin{tabular}{llll}
2013 & 0.10000 & 0.00083 & uniform \\
$2014-2017$ & 0.05000 & 0.00021 & uniform \\
\hline
\end{tabular}


Table 11 Results of one-way sensitivity analysis

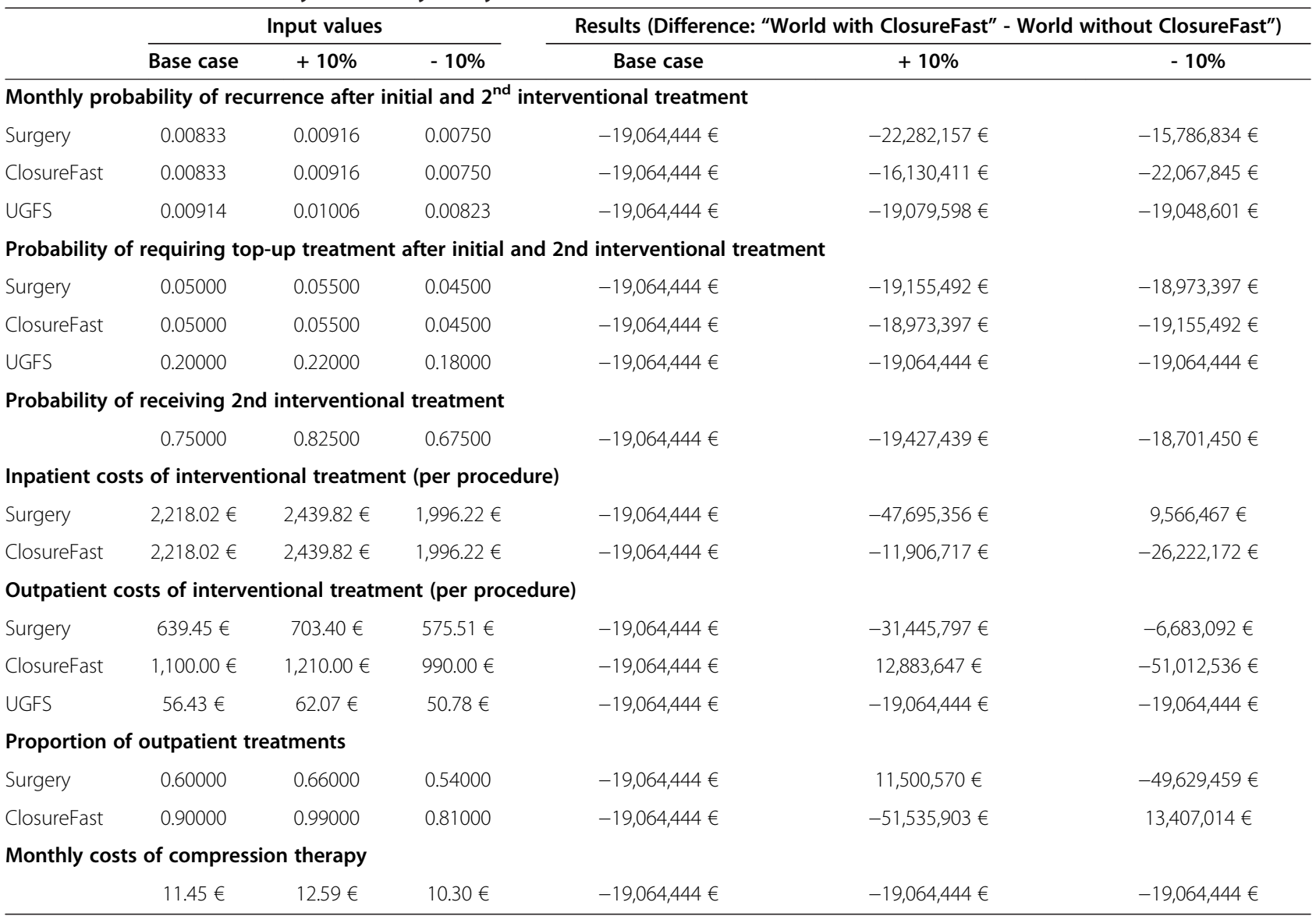

\section{Abbreviations}

BIA: Budget impact analysis; EVLA: Endovenous laser ablation;

PSA: Probabilistic sensitivity analysis; RFA: Radiofrequency ablation;

UGFS: Ultrasound guided foam sclerotherapy; SHI: Statutory health insurance.

\section{Competing interests}

The study is financially supported by Covidien.

\section{Authors' contributions}

AK has constructed the Markov model in Microsoft Excel. AK and AP gathered the necessary data as well as analyzed and interpreted the results. AK and AP have also writ-ten the manuscript. JMS and JH have revised the manuscript for important intellectual content. All authors have read and approved the final manuscript.

\section{Author details}

'Leibniz Universität Hannover, Center for Health Economics, Hannover, Germany. ${ }^{2}$ Oberender \& Partner, Bayreuth, Germany.

Received: 19 December 2012 Accepted: 19 March 2013

Published: 3 April 2013

\section{References}

1. Kluess HG, Noppeneya T, Breu FX, Ehresmann U, Gerlach HE, Hermanns HJ, Nüllen H, Pannier F, Salzmann G, Schimmelpfennig L, Schmedt CG, Steckmeier B, Stenger D: Leitlinie zur Diagnostik und Therapie der Krampfadererkrankung. Phlebologie 2010, 39:271-289.

2. London NJ, Nash R: $A B C$ of arterial and venous disease. Varicose veins. BMJ 2000, 320:1391-1394.
3. Bradbury A, Evans C, Allan P, Lee A, Ruckley CV, Fowkes FG: What are the symptoms of varicose veins? Edinburgh vein study cross sectional population survey. BMJ 1999, 318:353-356.

4. Campbell B: Varicose veins and their management. BMJ 2006, 333:287-292.

5. Butler CM, Coleridge Smith PD: Microcirculatory aspects of venous ulceration. J Dermato/ Surg Oncol 1994, 20:474-480.

6. Coleridge Smith PD: Pathogenesis of chronic venous insufficiency and possible effects of compression and pentoxifylline. Yale J Biol Med 1993, 66:47-59.

7. Callam MJ: Epidemiology of varicose veins. Br J Surg 1994, 81:167-173.

8. Evans CJ, Fowkes FG, Ruckley CV, Lee AJ: Prevalence of varicose veins and chronic venous insufficiency in men and women in the general population: Edinburgh Vein Study. J Epidemiol Community Health 1999, 53:149-153.

9. Carpentier PH, Maricq HR, Biro C, Ponçot-Makinen CO, Franco A: Prevalence, risk factors, and clinical patterns of chronic venous disorders of lower limbs: a population-based study in France. J Vasc Surg 2004, 40:650-659.

10. Robertson L, Evans C, Fowkes FGR: Epidemiology of chronic venous disease. Phlebology 2008, 23:103-111.

11. Widmer LK, Stähelin HB, Nissen C, Da Silva A: Venen-, Arterien-Krankheiten, koronare Herzkrankheit bei Berufstätigen. Prospektiv-epidemiologische Untersuchung. Basler Studien I-III. Bern: Huber; 1981.

12. Fischer H: Venenleiden - Eine repräsentative Untersuchung in der Bevölkerung der Bundesrepublik Deutschland (Tübinger Studie). München: Urban \& Schwarzenberg; 1981.

13. Rabe E, Pannier-Fischer F, Bromen K, Schuldt K, Stang A, Poncar C, Wittenhorst B, Bock E, Weber S, Jöckel K: Bonner Venenstudie der Deutschen Gesellschaft für Phlebologie. Epidemiologische Untersuchung zur Frage der Häufigkeit und Ausprägung von chronischen 
Venenkrankheiten in der städtischen und ländlichen Wohnbevölkerung Phlebologie 2003, 32:1-14.

14. Brand FN, Dannenberg AL, Abbott RD, Kannel WB: The epidemiology of varicose veins: the Framingham Study. Am J Prev Med 1988, 4:96-101.

15. Mäkivaara LA, Jukkola TM, Sisto T, Luukkaala T, Hakama M, Laurikka JO: Incidence of varicose veins in Finland. Vasa 2004, 33:159-163.

16. German Federal Statistical Office: Cost of illness accounts 2008. http:// www.gbe-bund.de.

17. Göckeritz O: Current standards and recent progress in minimally invasive phlebo surgery. J Cutan Aesthet Surg 2012, 5:104-114.

18. Rasmussen LH, Lawaetz M, Bjoern L, Vennits B, Blemings A, Eklof B: Randomized clinical trial comparing endovenous laser ablation, radiofrequency ablation, foam sclerotherapy and surgical stripping for great saphenous varicose veins. Br J Surg 2011, 98:1079-1087.

19. Nuijten MJC, Mittendorf T, Persson U: Practical issues in handling data input and uncertainty in a budget impact analysis. Eur J Health Econ 2011, 12:231-241.

20. Murad MH, Coto-Yglesias F, Zumaeta-Garcia M, Elamin MB, Duggirala MK, Erwin PJ, Montori VM, Gloviczki P: A systematic review and meta-analysis of the treatments of varicose veins. J Vasc Surg 2011, 53:49S-65S.

21. Dwerryhouse S, Davies B, Harradine K, Earnshaw Jj: Stripping the long saphenous vein reduces the rate of reoperation for recurrent varicose veins: five-year results of a randomized trial. J Vasc Surg 1999, 29:589-592.

22. Durkin MT, Turton EP, Wijesinghe LD, Scott DJ, Berridge DC: Long saphenous vein stripping and quality of life - a randomised trial. Eur J Vasc Endovasc Surg 2001, 21:545-549.

23. MacKenzie RK, Paisley A, Allan PL, Lee AJ, Ruckley CV, Bradbury AW: The effect of long saphenous vein stripping on quality of life. J Vasc Surg 2002, 35:1197-1203.

24. Critchley G, Handa A, Maw A, Harvey A, Harvey, Corbett CR: Complications of varicose vein surgery. Ann R Coll Surg Engl 1997, 79:105-110.

25. Michaels JA, Campbell WB, Brazier JE, Macintyre JB, Palfreyman SJ, Ratcliffe J, Rigby K: Randomised clinical trial, observational study and assessment of cost-effectiveness of the treatment of varicose veins (REACTIV trial). Health Technol Assess 2006, 10:1-196. iii-iv.

26. Rabe E, Gerlach HE, Breu FX, Guggenbichler S, Stücker M, Pannier F: Leitlinie: Sklerosierungsbehandlung der Varikose. Phlebologie 2012, 41:206-213.

27. Hobbs JT: Surgery and sclerotherapy in the treatment of varicose veins. Arch Surg 1974, 109:793-796.

28. Rutgers PH, Kitslar PJEHM: Randomized trial of stripping versus high ligation combined with sclerotherapy in the treatment of the incompetent greater saphenous vein. Am J Surg 1994, 168:311-315.

29. Ceulen RPM, Bullens-Goessens YIJM, de Pi-VAN Venne SJA, Nelemans PJ, Veraart JCJM, Sommer A: Outcomes and side effects of duplex-guided sclerotherapy in the treatment of great saphenous veins with $1 \%$ versus $3 \%$ polidocanol foam: results of a randomized controlled trial with 1-year follow-up. Dermatol Surg 2007, 33:276-281.

30. Hamel-Desnos C, Desnos P, Wollmann J, Ouvry P, Mako S, Allaert F: Evaluation of the efficacy of polidocanol in the form of foam compared with liquid form in sclerotherapy of the greater saphenous vein: initial results. Dermatol Surg 2003, 29:1170-5.

31. Rabe E, Otto J, Schliephake D, Pannier F: Efficacy and safety of great saphenous vein sclerotherapy using standardised polidocanol foam (ESAF): a randomised controlled multicentre clinical trial. Eur J Vasc Endovasc Surg 2008, 35:238-245.

32. Luebke T, Brunkwall J: Systematic review and meta-analysis of endovenous radiofrequency obliteration, endovenous laser therapy, and foam sclerotherapy for primary varicosis. J Cardiovasc Surg 2008, 49:213-233.

33. van den Bos R, Arends L, Kockaert M, Neumann M, Nijsten T: Endovenous therapies of lower extremity varicosities: a meta-analysis. $J$ Vasc Surg 2009, 49:230-239.

34. Rautio T, Ohinmaa A, Perälä J, Ohtonen P, Heikkinen T, Wiik H, Karjalainen P, Haukipuro K, Juvonen T: Endovenous obliteration versus conventional stripping operation in the treatment of primary varicose veins: a randomized controlled trial with comparison of the costs. J Vasc Surg 2002, 35:958-965.

35. Lurie F, Creton D, Eklof B, Kabnick LS, Kistner RL, Pichot O, Schuller-Petrovic $S$, Sessa C: Prospective randomized study of endovenous radiofrequency obliteration (closure procedure) versus ligation and stripping in a selected patient population (EVOLVeS Study). J Vasc Surg 2003, 38:207-214.
36. Perälä J, Rautio T, Biancari F, Ohtonen P, Wiik H, Heikkinen T, Juvonen T: Radiofrequency endovenous obliteration versus stripping of the long saphenous vein in the management of primary varicose veins: 3-year outcome of a randomized study. Ann Vasc Surg 2005, 19:669-672.

37. Colli R, Modugno P, Revelli L, Alberti V, Flore R, Santoliquido A: Termoablazione con radiofrequenza della vena grande safena versus stripping. Studio preliminare. [Endoluminal radiofrequency ablation of the great saphenous vein versus stripping. A preliminary study.]. Minerva Chir 2005, 60:481-486.

38. Hinchliffe RJ, Ubhi J, Beech A, Ellison J, Braithwaite BD: A prospective randomised controlled trial of VNUS closure versus surgery for the treatment of recurrent long saphenous varicose veins. Eur J Vasc Endovasc Surg 2006, 31:212-218.

39. Rasmussen LH, Bjoern L, Lawaetz M, Lawaetz B, Blemings A, Eklöf B: Randomised clinical trial comparing endovenous laser ablation with stripping of the great saphenous vein: clinical outcome and recurrence after 2 years. Eur J Vasc Endovasc Surg 2010, 39:630-635.

40. Pronk P, Gauw SA, Mooij MC, Gaastra MTW, Lawson JA, van Goethem AR, van Vlijmen-van Keulen CJ: Randomised controlled trial comparing sapheno-femoral ligation and stripping of the great saphenous vein with endovenous laser ablation (980 nm) using local tumescent anaesthesia: one year results. Eur J Vasc Endovasc Surg 2010, 40:649-656.

41. Darwood RJ, Theivacumar N, Dellagrammaticas D, Mavor AID, Gough MJ: Randomized clinical trial comparing endovenous laser ablation with surgery for the treatment of primary great saphenous varicose veins. Br J Surg 2008, 95:294-301.

42. Carradice D, Mekako Al, Mazari FAK, Samuel N, Hatfield J, Chetter IC: Clinical and technical outcomes from a randomized clinical trial of endovenous laser ablation compared with conventional surgery for great saphenous varicose veins. Br J Surg 2011, 98:1117-1123.

43. Mauskopf JA, Sullivan SD, Annemans L, Caro J, Mullins CD, Nuijten M, Orlewska E, Watkins J, Trueman P: Principles of good practice for budget impact analysis: report of the ISPOR Task Force on good research practices-budget impact analysis. Val Health 2007, 10:336-347.

44. National Institute for Health and Clinical Excellence (NICE) (Ed): Varicose veins in the legs. The diagnosis and management of varicose veins. http:// www.nice.org.uk/guidance/index.jsp?action $=$ download\&o $=62743$.

45. National Institute for Health and Clinical Excellence (NICE) (Ed): Varicose Veins. Appendices A-O. http://www.nice.org.uk/guidance/index.jsp? action $=$ download\&o $=62751$.

46. German Federal Statistical Office: Mortality data 2009/2011. https://wwwgenesis.destatis.de/genesis/online.

47. German Federal Statistical Office: DRG statistics (hospital statistics based on case flat rates) 2011. http://www.destatis.de.

48. German Federal Statistical Office: Number of members and jointly insured family members of the statutory health insurance. http://www.gbe-bund.de.

49. Fischer R, Chandler JG, Stenger D, Puhan MA, de Maeseneer MG, Schimmelpfennig L: Patient characteristics and physician-determined variables affecting saphenofemoral reflux recurrence after ligation and stripping of the great saphenous vein. J Vasc Surg 2006, 43:81-87.

50. Pavei P, Vecchiato M, Spreafico G, Giraldi E, Ferrini M, Baccaglini U, Ancona E: Natural history of recurrent varices undergoing reintervention: a retrospective study. Dermatol Surg 2008, 34:1676-1682.

51. van Rij AM, Jiang P, Solomon C, Christie RA, Hill GB: Recurrence after varicose vein surgery: a prospective long-term clinical study with duplex ultrasound scanning and air plethysmography. J Vasc Surg 2003, 38:935-943.

52. Bradbury AW, Stonebridge PA, Callam MJ, Walker AJ, Allan PL, Beggs I, Ruckley CV: Recurrent varicose veins: assessment of the saphenofemoral junction. Br J Surg 1994, 81:373-375.

53. Darke SG: The morphology of recurrent varicose veins. Eur J Vasc Surg 1992, 6:512-517.

54. Rabe E, Bauersachs RM, Pannier F, List SM: Venenerkrankungen der Beine. [Venous disease of the lower extremities.]. Berlin: Robert-Koch-Inst; 2009.

55. Noppeney T, Nüllen H: Die Rezidivvariksoe - Was ist das? Gefäßchirurgie 2005, 10:424-427.

56. van Groenendael $L$, van der Vliet JA, Flinkenflögel $L$, Roovers EA, van Sterkenburg SMM, Reijnen MMPJ: Treatment of recurrent varicose veins of the great saphenous vein by conventional surgery and endovenous laser ablation. J Vasc Surg 2009, 50:1106-1113. 
57. Campbell WB, Vijay Kumar A, Collin TW, Allington KL, Michaels JA: The outcome of varicose vein surgery at 10 years: clinical findings, symptoms and patient satisfaction. Ann R Coll Surg Engl 2003, 85:52-57.

58. Winterborn RJ, Foy C, Earnshaw JJ: Causes of varicose vein recurrence: late results of a randomized controlled trial of stripping the long saphenous vein. J Vasc Surg 2004, 40:634-639.

59. Chiesa R, Marone EM, Limoni C, Volontè M, Petrini O: Chronic venous disorders: correlation between visible signs, symptoms, and presence of functional disease. J Vasc Surg 2007, 46:322-330.

60. Brar R, Nordon IM, Hinchliffe RJ, Loftus IM, Thompson MM: Surgical management of varicose veins: meta-analysis. Vascular 2010, 18:205-220.

61. Nesbitt C, Eifell RK, Coyne P, Badri H, Bhattacharya V, Stansby G: Endovenous ablation (radiofrequency and laser) and foam sclerotherapy versus conventional surgery for great saphenous vein varices. Cochrane Database Syst Rev 2011. CD005624.

62. Siribumrungwong B, Noorit P, Wilasrusmee C, Attia J, Thakkinstian A: A systematic review and meta-analysis of randomised controlled trials comparing endovenous ablation and surgical intervention in patients with varicose vein. Eur J Vasc Endovasc Surg 2012, 44:214-223.

63. Belcaro G, Nicolaides AN, Ricci A, Dugall M, Errichi BM, Vasdekis S, Christopoulos D: Endovascular sclerotherapy, surgery, and surgery plus sclerotherapy in superficial venous incompetence: a randomized, 10-year follow-up trial-final results. Angiology 2000, 51:529-534.

64. Lurie F, Creton D, Eklof B, Kabnick LS, Kistner RL, Pichot O, Sessa C, SchullerPetrovic S: Prospective randomised study of endovenous radiofrequency obliteration (closure) versus ligation and vein stripping (EVOLVeS): twoyear follow-up. Eur J Vasc Endovasc Surg 2005, 29:67-73.

65. Helmy EIKaffas K, ElKashef O, ElBaz W: Great saphenous vein radiofrequency ablation versus standard stripping in the management of primary varicose veins-a randomized clinical trial. Angiology 2011, 62:49-54.

66. Shadid N, Ceulen R, Nelemans P, Dirksen C, Veraart J, Schurink GW, van Neer P, vd Kley J, de Haan E, Sommer A: Randomized clinical trial of ultrasound-guided foam sclerotherapy versus surgery for the incompetent great saphenous vein. Br J Surg 2012, 99:1062-1070.

67. Braun S, Prenzler A, Mittendorf T, von der Schulenburg JM: Bewertung von Ressourcenverbräuchen im deutschen Gesundheitswesen aus Sicht der Gesetzlichen Krankenversicherung [Appraisal of valuation of resource use in the German healthcare system from the perspective of the statutory health insurance]. Gesundheitswesen 2009, 71:19-23.

68. Prenzler A, Zeidler J, Braun S, von der Schulenburg JM: Bewertung von Ressourcen im Gesundheitswesen aus der Perspektive der deutschen Sozialversicherung [Assessment of health care resources from the viewpoint of the German social insurance system]. PharmacoEconomics German Research Articles 2010, 8:47-66.

69. InEK GmbH - Institute for the Hospital Remuneration System: Diagnosis Related Group-Catalogue 2012. Düsseldorf: Dt. Krankenhaus-Verl.-Ges; 2011.

70. InEK GmbH - Institute for the Hospital Remuneration System: G-DRG Definition Handbook, Version 2012. Düsseldorf: Dt. Krankenhaus-Verl.-Ges; 2011.

71. National Association of Statutory Health Insurance Physicians: Uniform Value Scale 2012. http://www.kbv.de.

72. Kemper C, Sauer K, Glaeske G: Barmer-GEK-Heil- und Hilfsmittel-Report. Schriftenreihe zur Gesundheitsanalyse, vol. 16. Asgard: Sankt Augustin; 2012.

73. Institute for Quality and Efficiency in Health Care: Working Paper on Cost Estimation in health economic evaluations. https:/www.iqwig.de/ download/Working_Paper_Cost_Estimation.pdf.

74. Nüllen H, Noppeney T: Ambulante Varizenoperation. Phlebologie 2011, 40:61-66.

75. Medical Advisory Secretariat: Endovascular radiofrequency ablation for varicose veins: an evidence-based analysis. http://www.health.gov.on.ca/ english/providers/program/mas/tech/reviews/pdf/rev_rfa_wv_20110216.pdf.

76. Gohel MS, Epstein DM, Davies AH: Cost-effectiveness of traditional and endovenous treatments for varicose veins. Br J Surg 2010, 97:1815-1823.

doi:10.1186/2191-1991-3-9

Cite this article as: Kuhlmann et al:: Impact of radiofrequency ablation for patients with varicose veins on the budget of the German statutory health insurance system. Health Economics Review 2013 3:9.

\section{Submit your manuscript to a SpringerOpen ${ }^{\circ}$ journal and benefit from:}

- Convenient online submission

- Rigorous peer review

- Immediate publication on acceptance

- Open access: articles freely available online

- High visibility within the field

- Retaining the copyright to your article 